\title{
Editorial
}

\section{Yoga and Rehabilitation: Physical, Psychological, and Social}

\author{
Shirley Telles, ${ }^{1}$ Elisa Kozasa, ${ }^{2,3}$ Luciano Bernardi, ${ }^{4,5}$ and Marc Cohen ${ }^{6}$ \\ ${ }^{1}$ Patanjali Research Foundation, Haridwar, India \\ ${ }^{2}$ Hospital Israelita Albert Einstein, 05651-901 São Paulo, SP, Brazil \\ ${ }^{3}$ Department of Psychobiology, Universidade Federal de São Paulo, 04023-062 São Paulo, SP, Brazil \\ ${ }^{4}$ Department of Internal Medicine, University of Pavia, Italy \\ ${ }^{5}$ Folkhälsan Research Center, University of Helsinki, Finland \\ ${ }^{6}$ Royal Melbourne Institute of Technology, Melbourne, VIC, Australia \\ Correspondence should be addressed to Shirley Telles; shirleytelles@gmail.com
}

Received 30 September 2013; Accepted 30 September 2013

Copyright (C) 2013 Shirley Telles et al. This is an open access article distributed under the Creative Commons Attribution License, which permits unrestricted use, distribution, and reproduction in any medium, provided the original work is properly cited.

Yoga was intended for spiritual evolution [1], but increasingly nowadays it is used for its incidental benefits such as stress reduction and managing lifestyle related disorders. Despite its Indian origin, the number of yoga practitioners in Western society is growing: in the United States, for example, a national survey showed that $6.1 \%$ of the adults were practicing yoga in 2007 [2].

Apart from the benefits of Yoga practice in preventing and managing disease, yoga has several applications in rehabilitation (rehabilitare $=$ to restore, in Latin). Rehabilitation is of different types such as (i) physical, (ii) psychological, and (iii) social. Yoga, as a way of life, has helped persons with physical disorders to return to health, an example being coronary artery disease $[3,4]$. Other conditions which have benefitted from yoga practice include stroke after cerebrovascular accidents [5] and patients with heart failure, in whom exercise capacity, oxygen saturation, and parasympathetic activity were restored $[6,7]$. Yoga breathing or pranayama was especially beneficial for COPD [8]. Practicing yoga has also been used with good results in degenerative disorders such as idiopathic Parkinson's syndrome [9] and muscular dystrophy [10].

With regard to psychological rehabilitation, yoga practice has helped restore the psychological function and mental equilibrium in persons with posttraumatic stress disorder [11] and even certain psychotic conditions [12].

Finally, yoga practice can help people who are at a disadvantage because of their social circumstances. This includes persons in jail [13], those from the "inner city" [14], children in remand homes $[15,16]$, and older people living in community centers $[17,18]$. Social rehabilitation includes dimensions of physical and psychological rehabilitation.

Despite the research cited above, there is a continued need for research. A summary of yoga reviews pointed to the importance of larger-scale, rigorous research with higher methodological quality and adequate control groups.

Additionally, it should be stressed that although research should be aimed at yoga as a whole (hence including postures as well as meditation, respiratory practices, diet, and other aspects) this is obviously very complex, as the contribution of many different aspects cannot be easily identified, and confounding factors may play a decisive role. Also, the complexity and variety of different yoga techniques make a comparison between different studies very difficult. On the other hand, a "reductionist" approach seems to be more feasible from a scientific point of view, due to an easier separation of the specific effects of a single intervention (e.g., the analysis of one posture or the analysis of a single type of pranayama), but it is obviously at the risk of missing the whole effect of yoga. As a typical example, if one measures only the energy expenditure of a single yoga session, one may conclude that yoga will be of no use to lose weight, but other crucial effects of yoga related to weight control could be missed, such as the attention to diet and possibly a direct effect of pranayama on the hypothalamus, through which yoga does actually lead to weight loss. Thus, a careful balance between these opposite aspects needs to be taken into account when planning research on yoga. 
The analyzed reviews suggested a number of areas where yoga may be beneficial, but more research is required for them to really establish such benefits. Nevertheless, some metaanalyses indicated that there are several randomized clinical trials of relatively high quality indicating beneficial effects of yoga for pain-associated disability and mental health [8]. Considering the large number of different yoga techniques and schools of yoga, it is also important for researchers to describe, in detail, the specific method used in a given study.

Yoga is worth investigating as it is relatively cost-effective, its practices can be adapted for different groups of patients, and if well oriented, the risks of side effects are very low. We hope that this special issue will give new insights for the development of novel, well-designed studies in the field of yoga and rehabilitation.

\section{Shirley Telles Elisa Kozasa Luciano Bernardi Marc Cohen}

\section{References}

[1] G. Feuerstein, The Yoga Tradition, Hohm Press, Prescott, Ariz, USA, 3rd edition, 2002.

[2] P. M. Barnes, B. Bloom, and R. L. Nahin, "Complementary and alternative medicine use among adults and children: United States, 2007," National Health Statistics Reports 12, National Center for Health Statistics, Hyattsville, Md, USA, 2008.

[3] D. Ornish, S. E. Brown, L. W. Scherwitz et al., "Can lifestyle changes reverse coronary heart disease?" The Lancet, vol. 336, no. 8708 , pp. $129-133,1990$.

[4] S. C. Manchanda, R. Narang, K. S. Reddy et al., "Retardation of coronary atherosclerosis with yoga lifestyle intervention," Journal of Association of Physicians of India, vol. 48, no. 7, pp. 687694, 2000.

[5] A. A. Schmid, M. Van Puymbroeck, P. A. Altenburger et al., "Poststroke balance improves with yoga: a pilot study," Stroke, vol. 43, no. 9, pp. 2402-2407, 2012.

[6] L. Bernardi, C. Porta, L. Spicuzza et al., "Slow breathing increases arterial baroreflex sensitivity in patients with chronic heart failure," Circulation, vol. 105, no. 2, pp. 143-145, 2002.

[7] L. Bernardi, G. Spadacini, J. Bellwon, R. Hajric, H. Roskamm, and A. W. Frey, "Effect of breathing rate on oxygen saturation and exercise performance in chronic heart failure," The Lancet, vol. 351, no. 9112, pp. 1308-1311, 1998.

[8] T. Raupach, F. Bahr, P. Herrmann et al., "Slow breathing reduces sympathoexcitation in COPD," European Respiratory Journal, vol. 32, no. 2, pp. 387-392, 2008.

[9] E. Hall, G. Verheyden, and A. Ashburn, "Effect of a yoga programme on an individual with Parkinson's disease: a singlesubject design," Disability and Rehabilitation, vol. 33, no. 15-16, pp. 1483-1489, 2011.

[10] S. Telles, A. Balkrishna, and K. Maharana, "Effect of yoga and ayurveda on duchenne muscular dystrophy," Indian Journal of Palliative Care, vol. 17, no. 2, pp. 169-170, 2011.

[11] S. Telles, N. Singh, M. Joshi, and A. Balkrishna, "Post traumatic stress symptoms and heart rate variability in Bihar flood survivors following yoga: a randomized controlled study," $B M C$ Psychiatry, vol. 10, article 18, 2010.
[12] S. Varambally, S. Vidyendaran, M. Sajjanar et al., "Yoga-based intervention for caregivers of outpatients with psychosis: a randomized controlled pilot study," Asian Journal of Psychiatry, vol. 6, no. 2, pp. 141-145, 2013.

[13] S. V. Vyavahare, "Yoga for jail inmates," in Proceedings of the 1st International Conference on Frontiers in Yoga Research and Applications, VKYRF, Bangalore, India, December 1991.

[14] D. L. Berger, E. J. Silver, and R. E. K. Stein, "Effects of yoga on inner-city children's well-being: a pilot study," Alternative Therapies in Health and Medicine, vol. 15, no. 5, pp. 36-42, 2009.

[15] S. Telles, S. Narendran, P. Raghuraj, R. Nagarathna, and H. R. Nagendra, "Comparison of changes in autonomic and respiratory parameters of girls after Yoga and games at a community home," Perceptual and Motor Skills, vol. 84, no. 1, pp. 251-257, 1997.

[16] P. Raghuraj and S. Telles, "Muscle power, dexterity skill and visual perception in community home girls trained in yoga or sports and in regular school girls," Indian Journal of Physiology and Pharmacology, vol. 41, no. 4, pp. 409-415, 1997.

[17] M. N. Krishnamurthy and S. Telles, "Assessing depression following two ancient Indian interventions: effects of Yoga and Ayurveda on older adults in a residential home," Journal of Gerontological Nursing, vol. 33, no. 2, pp. 17-23, 2007.

[18] N. K. Manjunath and S. Telles, "Influence of Yoga \& Ayurveda on self-rated sleep in a geriatic population," Indian Journal of Medical Research, vol. 121, no. 5, pp. 683-690, 2005. 


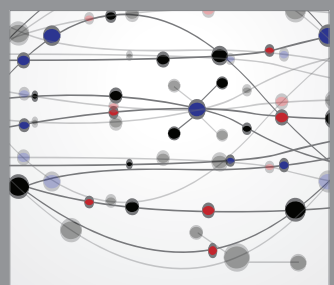

The Scientific World Journal
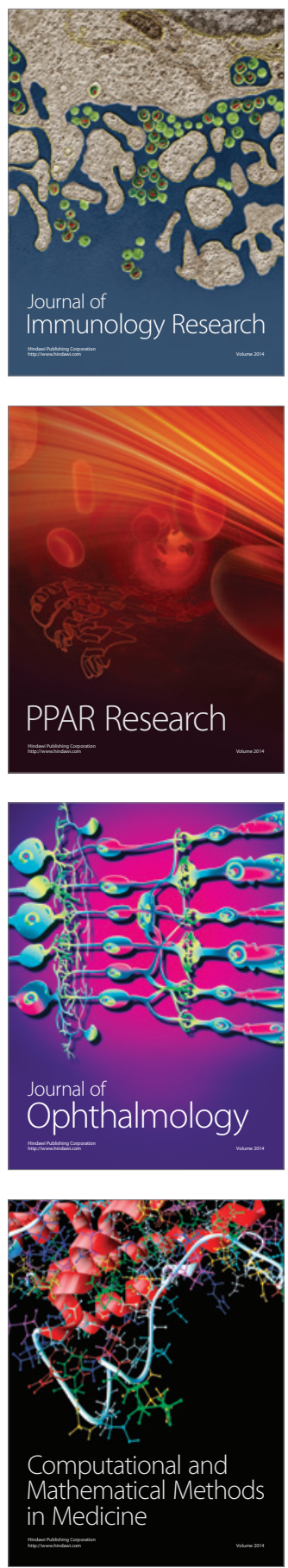

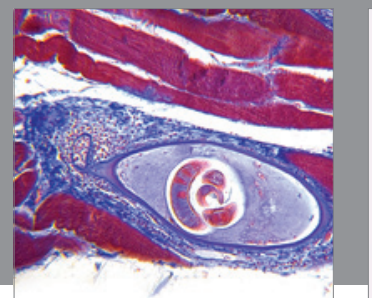

Gastroenterology

Research and Practice
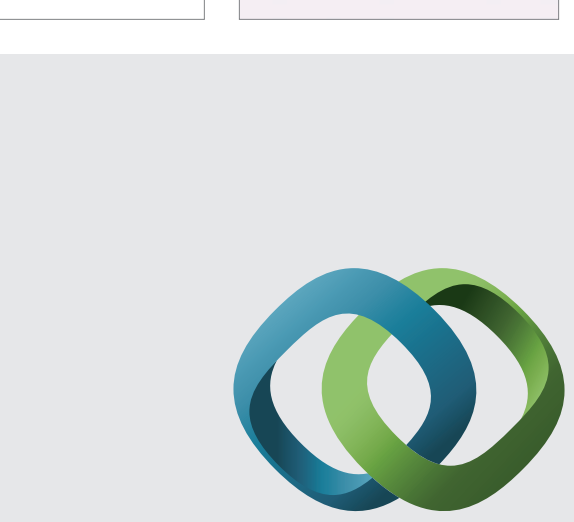

\section{Hindawi}

Submit your manuscripts at

http://www.hindawi.com
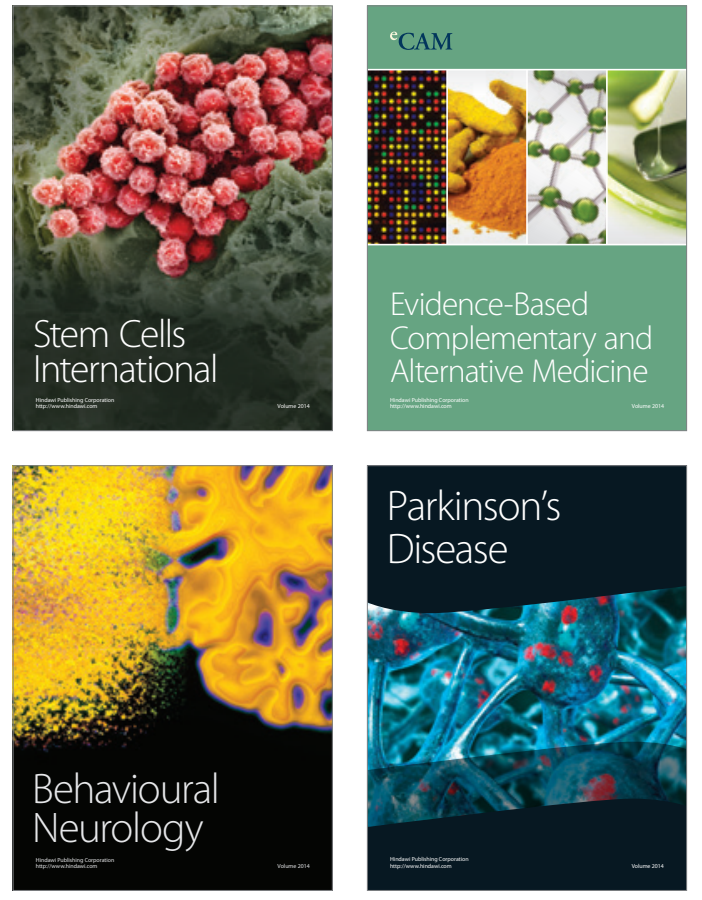
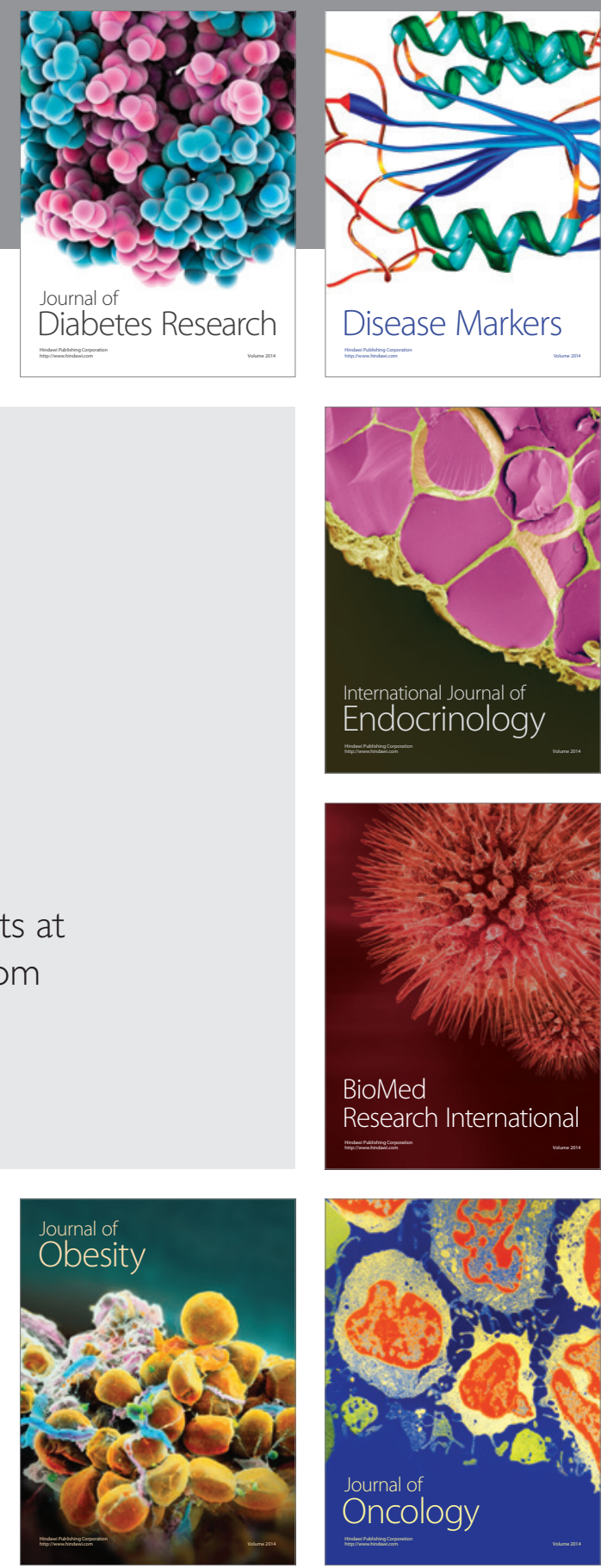

Disease Markers
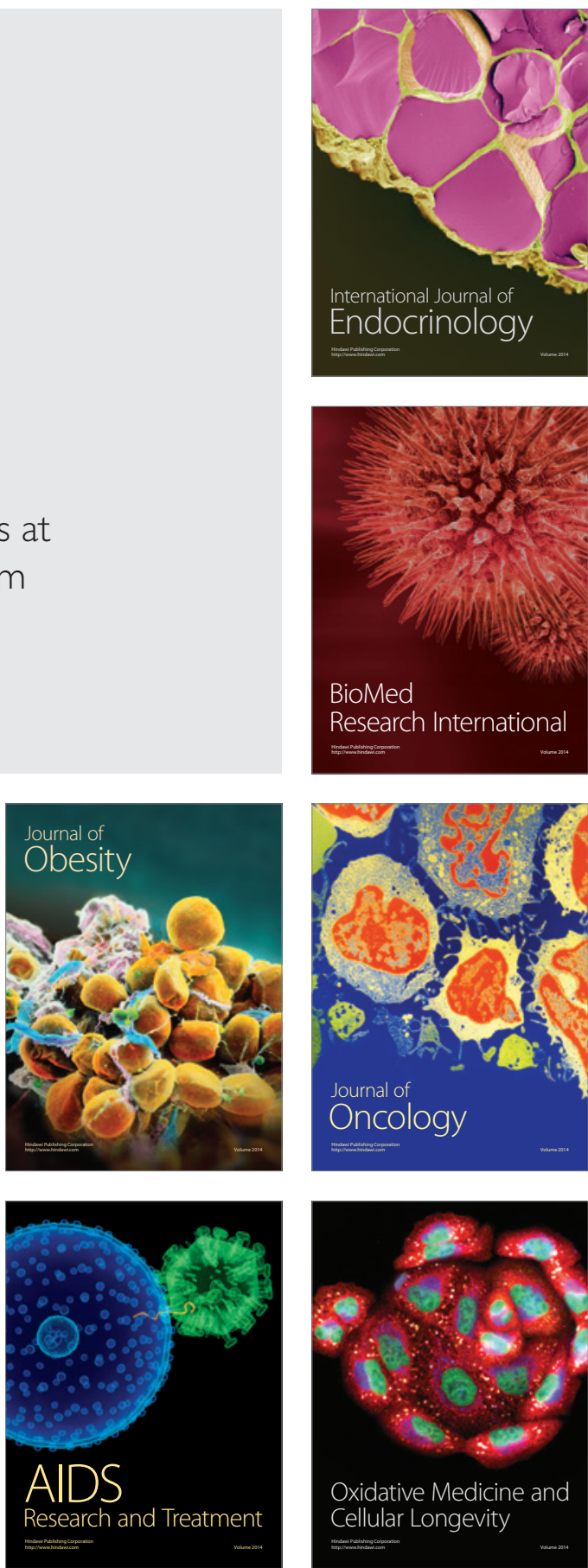